\title{
A late complication of a diagnostic mediastinoscopy
}

\author{
H. F. W. HOITSMA ${ }^{1}$, E. T. T. TJHO ${ }^{2}$, AND M. A. CUESTA ${ }^{1}$
}

From the Departments of General Surgery ${ }^{1}$ and Thoracic Medicine ${ }^{2}$, Het Academisch Ziekenhuis der Vrije Universiteit, Amsterdam, The Netherlands

Hoitsma, H. F. W., Tjho, E. T. T., and Cuesta, M. A. (1978). Thorax, 33, 115-116. A late complication of a diagnostic mediastinoscopy. A 69-year-old man with a moderately well differentiated squamous-cell carcinoma of the lung, underwent a mediastinoscopy. All histological examinations of the mediastinal nodes were negative. The patient was treated with a curative left pneumonectomy. Three months after this negative mediastinoscopy the patient developed a metastasis in the mediastinoscopy scar. A report of this case and a review of the literature are presented.

In 1959, Carlens wrote the article, which has since become famous, entitled 'Mediastinoscopy: a method for inspection and tissue biopsy in the superior mediastinum'. He described a method which he had developed in order to assess the stage of lymphatic metastasis of carcinoma of the lung. Since its introduction it has become a much used method to avoid unnecessary thoracotomies.

It is known that mediastinoscopy used purely for diagnostic purposes can be accompanied by complications. One of the late complications is cell-implanted metastasis in the area of the mediastinoscopy incision, an event up to this time always described in association with positive mediastinoscopy findings. The following case is reported to emphasise that cell-implanted metastasis can occur even after a negative mediastinoscopy.

\section{Case report}

A 69-year-old man attended the lung department with a history of progressive cough and occasional blood in the sputum. The patient had had no previous lung complaints. A pathological lesion in the dorsal part of the left lower lobe was found. Bronchography showed complete occlusion of the left lower lobe bronchus. Tumour biopsy during bronchoscopy revealed a moderate to well differentiated squamous-cell carcinoma. The investigation was extended to a mediastinoscopy. No abnormalities were found on palpation of the anterior superior mediastinum. Nodes were seen in the right and left paratracheal area as well as next to the left and right main bronchi and in the carinal area. Specimens of tissue were taken from all of them at biopsy. Histological investigation of the biopsy specimens showed fragmented and complete lymph nodes with an intact structure. Besides anthracotic infiltration there was a firm, histiocytic reaction. No tumour cells were found.

Ten days later the patient underwent a left pneumonectomy. All visible nodes in the hilus and in the carinal area were also resected. The postoperative course was uneventful. Histological investigation of the excised lung tissue revealed an infiltrating, moderately differentiated, squamouscell carcinoma in the lateral basal segment of the left lower lobe. Two peribronchial nodes localised in the main fissure contained metastases. All the

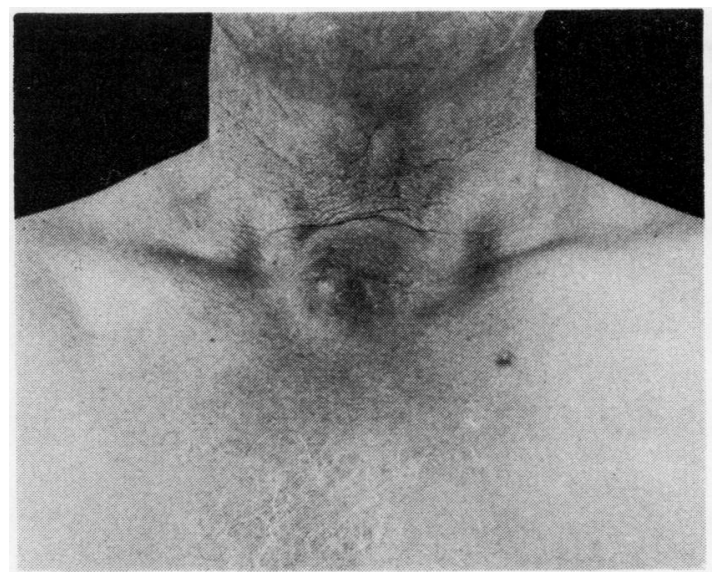

Figure Metastasis at site of mediastinoscopy skin incision. 
remaining nodes were negative. At the site of bronchial division no tumour cells were found.

At the follow-up, three months after the pneumonectomy, a swelling was seen in the mediastinoscopy scar (Figure). This swelling grew within the skin and extended to the back of the sternum. The opinion that this could be a cellimplanted metastasis was confirmed by histological examination of a biopsy specimen from the tumour. A moderately differentiated, infiltrating, squamous-cell carcinoma was found.

\section{Discussion}

In our clinic 547 mediastinoscopies were performed for malignant pulmonary tumours between 1965 and 1976, and only in the reported case was a cell-implanted metastasis found (three months after performing the mediastinoscopy). It must be stressed that the mediastinoscopy was negative. Also, at a later review of the biopsy specimen, no metastasis could be demonstrated.

Reynders (1964) saw in his series of 164 mediastinoscopies two cases of cell-implanted metastasis. In both cases the mediastinoscopy was positive. van der Schaar and van Zanten (1965) had one case out of 145 mediastinoscopies, Freise and Schüler (1965) had one patient. Ashbaugh (1970) found eight cases in a review of 6490 mediastinoscopies, and Rink and Knoche (1970), with nine cases in 6986 patients, had a $0.15 \%$ incidence of scar metastasis.

Gunstensen and Wade (1972), out of 320 mediastinoscopies, found one case with tumour invasion of the suprasternal scar three months after mediastinoscopy in a patient with extensive neoplastic involvement of the mediastinum.

R. N. Sapsford (personal communication, 1977) found in his series of 1675 mediastinoscopies three patients with cell-implanted metastases. All series show nearly the same incidence-in the region of $0.18 \%$. In all these reported cases tumour-positive biopsies were taken at mediastinoscopy.

The curious thing is that in our patient no tumour cells were found in the lymph nodes which were removed at biopsy. Even so, a cell-implanted metastasis was discovered. The operation that was performed appeared (macroscopically as well as microscopically) to be curative. Presumably during preparation for mediastinoscopy the lymph tracts were opened along the left main bronchus, from where the migration of tumour cells took place. The question now arises how far this diagnostic procedure nullifies the eventual curative aim of the resection.

\section{References}

Ashbaugh, D. G. (1970). Mediastinoscopy. Archives of Surgery, 100, 568-573.

Carlens, E. (1959). Mediastinoscopy; A method for inspection and tissue biopsy in the superior mediastinum. Diseases of the Chest, 36, 343-352.

Freise, G., and Schüler, W. (1965). Probe Exzision und Probe Punktion beim Bronchialkarzinom. Münchener medizinische Wochenschrift, 107, 947-950.

Gunstensen, J., and Wade, J. D. (1972). Mediastinoscopy. An analysis of 320 consecutive cases. British Journal of Surgery, 59, 209-213.

Reynders, H. (1964). Mediastinoscopy in bronchogenic cancer. Diseases of the Chest, 45, 606-611.

Rink, H., and Knoche, E. (1970). Mediastinoskopie. Der Chirurg, 41, 1-8.

Schaar, P. J. van der, and Zanten, M. E. van (1965). Experience with mediastinoscopy. Thorax, 20, 211213.

Requests for reprints to: Dr. H. F. W. Hoitsma, Department of Surgery, Academische Ziekenhuis der Vrije Universiteit, de Baelehaan 117, Amsterdam, The Netherlands. 